\title{
Academic partnerships 2016
}

\section{Brady Huggett}

Dreclinical deals between industry and academia dipped in 2016 to

207, down from 236 the year prior, continuing the long slide since 395 deals were formed in 2012. Industry remains interested in academic research but has gotten more selective about why and how it forms deals. The school systems of California and Texas again are in this list as the most active schools, but it is the University of Pennsylvania that made a large jump: nine deals in 2016 versus four in 2015 (Table 1). AstraZeneca and Johnson \& Johnson are atop the list of most-active pharmas and big biotechs in 2016 (Fig. 1), with Johnson \& Johnson moving from 3 deals in 2015 to 11 last year.

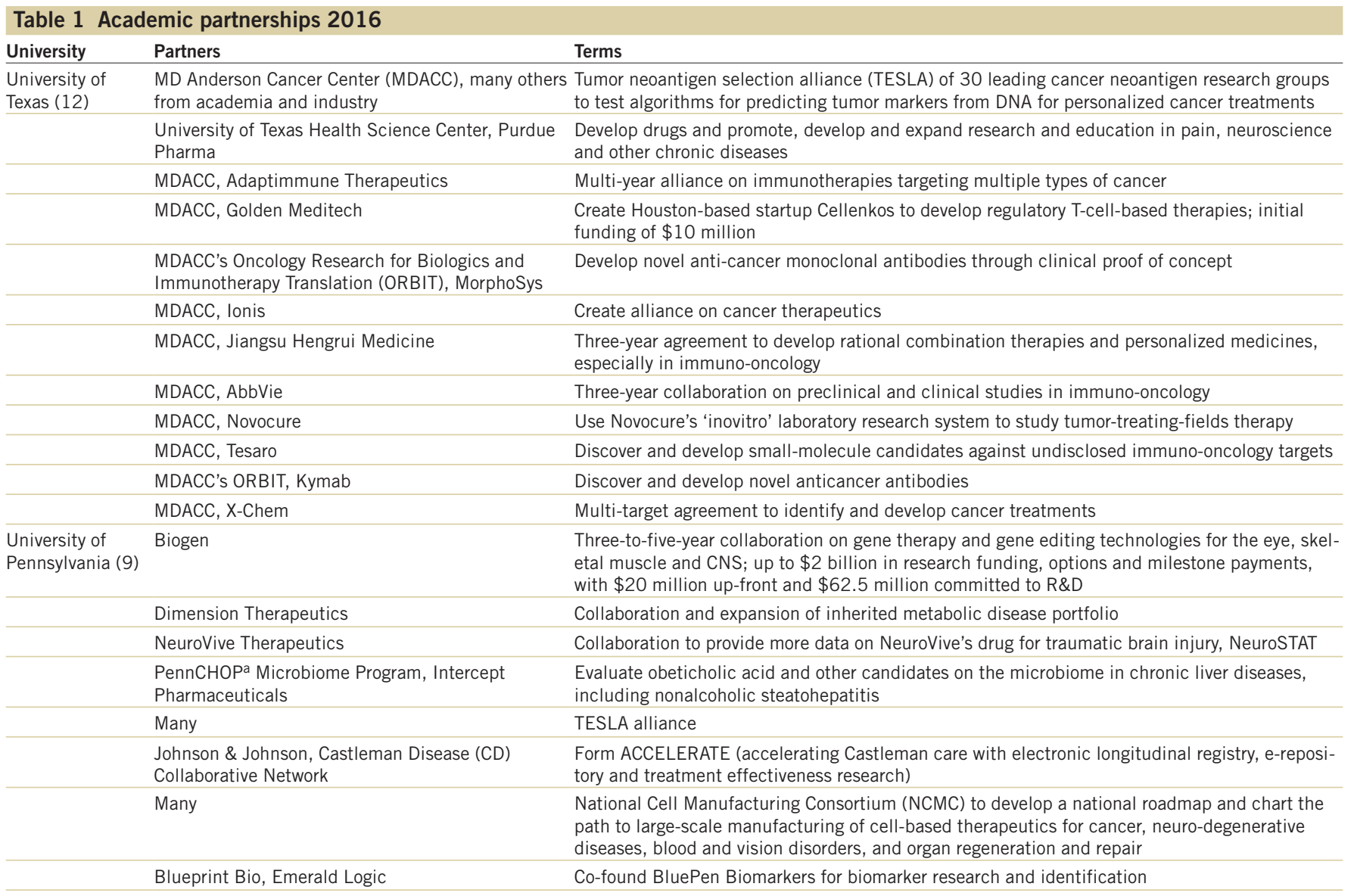

Celgene, Abramson Cancer Center at the University Consortium aligning Celgene and four academic institutions on cancer; Celgene also providing of Pennsylvania, The Herbert Irving Comprehensive $\$ 12.5$ million to each institution

Cancer Center at Columbia University Medical

Center, Sidney Kimmel Comprehensive Cancer

Center at Johns Hopkins, Tisch Cancer Institute at

the Icahn School of Medicine at Mount Sinai

University of UC Los Angeles, UC San Francisco, UC Santa Cruz, TESLA alliance

California (UC; 8) many others

UC San Francisco, Selvita

UC Berkeley, many others

UC San Francisco, many others

UC Berkeley, Aduro Biotech

UC San Diego, Samsara/Organovo

UC San Francisco, MedImmune/AstraZeneca
Focus on neurodegenerative disease, with Selvita doing the chemical synthesis, purification, structure determination and purity analysis of small molecules

NCMC

National Cancer Institute (NCl) renews the Chemical Biology Consortium, the discovery engine for the NCl Experimental Therapeutics (NExT) Program

Work on cancer, infectious disease and autoimmune disease via UC-Berkeley's Immunotherapeutics and Vaccine Research Initiative

Advance liver tissue models

Focus on respiratory, inflammation and autoimmunity area with an emphasis on basic research and translational sciences

Collaboration to identify targets for Chagas disease

UC San Diego, Johnson \& Johnson

aPennCHOP, U Penn and Children's Hospital of Philadelphia. Other universities with deals: Harvard (7), and another three deals formed by the Broad Institute of MIT and Harvard; Stanford (6); University of Chicago, University of Oxford, Baylor College of Medicine, Weill Cornell, each with four deals. Source: BCIQ: BioCentury Online Intelligence. 


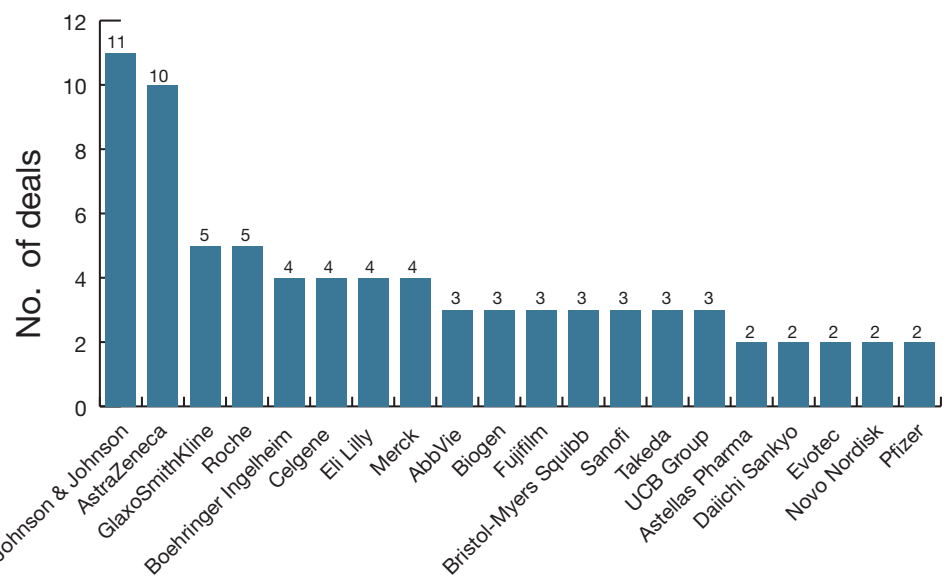

Figure 1 The most-active pharmas and big biotechs with academic or research institute partners in 2016. Source: BCIQ: BioCentury Online Intelligence.

Brady Huggett is Business Editor at Nature Biotechnology.

\section{PODCAST}

\section{First rounders: Rachel Haurwitz}

Rachel Haurwitz is co-founder, president and CEO of Caribou Biosciences. In her discussion with Nature Biotechnology, she explains what drew her into the sciences, how her father's journalism career brought their family to Austin, Texas, and how she found herself at the cutting edge of CRISPR technology. http://www. nature. $\mathrm{com} / \mathrm{nbt} /$ podcast/index.html

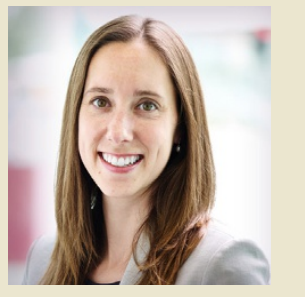

